\title{
Representación sociolingüística de lo rural mediante recursos de oralidad simulada en dos obras teatrales de Roberto Navarrete
}

\author{
Daniel Ignacio Pereira ${ }^{1}$ \\ Universidad de Concepción, Chile \\ Patricia Henriquez Puentes \\ Universidad de Concepción, Chile \\ Juan Pablo Amaya \\ Universidad de Concepción, Chile \\ Nicolás Masquiarán \\ Universidad de Concepción, Chile
}

\begin{abstract}
Resumen
Bajo el concepto de oralidad simulada, en este artículo se realiza una caracterización sociolingüística de dos obras inéditas de temática campesina del dramaturgo nacional Roberto Navarrete: El cochayuyero y La mariposa en el barbecho. Para ello, se rastrearon los recursos fónicos, léxicos y morfosintácticos que el autor seleccionó para representar el habla de los personajes rurales
\end{abstract}

\footnotetext{
Para correspondencia, dirigirse a: Daniel Ignacio Pereira (danielpereira@udec.cl), Universidad de Concepción, Departamento de Español, Casilla 160-C, Correo 3, Concepción, Chile.
} 
de los textos analizados y, a partir de ello, se propone una lectura de recentralización de lo campesino en el teatro de la época.

Palabras clave: representación sociolingüística, oralidad simulada, teatro, habla rural.

\section{SOCIOLINGUISTIC REPRESENTATION OF RURALITY BY THE MEANS OF SIMULATED ORALITY IN TWO PLAYS BY ROBERTO NAVARRETE}

Abstract

Under the concept of simulated orality, this article provides a sociolinguistic characterization of two rural-themed plays by the Chilean dramatist Roberto Navarrete: El cochayuyero and $\mathrm{La}$ Mariposa en el barbecho. In order to achieve this, the phonic, lexical and morphosyntactic resources selected by the author to represent rurality in the texts were identified and, from that, a recentralization interpretation of rurality in the theater of the time is proposed.

Keywords: sociolinguistic representation, simulated orality, theater, rural speech.

Recibido: 03/01/18 Aceptado: $30 / 04 / 18$

\section{INTRODUCCIÓN²}

¿Por qué habiamos de vivir condenados a no pronunciar más palabras que las que salieron de la boca de Garcilaso o Cervantes?

José María Núñez

Varios estudios sobre oralidad o relacionados con la variedad oral de la lengua han extraído sus datos y ejemplos de textos dramáticos (Cf. Martínez 1993; Oesterreicher 1996; Narbona 2012), sobre todo cuando no se contaba con registros auditivos de las realizaciones fonéticas o conversacionales de

2 Este artículo forma parte del proyecto FONDART de Investigación $\mathrm{N}^{\circ} 413750$, "Roberto Navarrete Troncoso, dramaturgo del TUC: La escena inconclusa". 
una determinada diacronía, pues la obra dramática, sobre todo aquella de estética realista, estereotipa la realidad de su contexto de producción para hacer patente a los lectores o espectadores la caracterización de determinados personajes. De este modo, los fenómenos que en el habla real ocurren no solo son puestos al servicio de la construcción de caracteres o de ambientes de la obra, sino que también constituyen "tácticas de representación sociolingüística mediante la escritura", como señala Fuentes González (2017: 107).

El habla que se ofrece al lector en algunas obras dramáticas no es más que un recurso literario denominado por Eberenz (2001) como oralidad simulada o fingida (Mancera 2008), es decir, una mímesis de la forma de hablar de determinados estratos sociales o geográficos. Pero,

dichas imitaciones nunca son completas, sino que más bien reflejan la voluntad y conciencia del autor que al fin y al cabo es quien selecciona ciertos rasgos como característicos de la lengua hablada, con resultados más o menos logrados según los casos (Eberenz 2001: 131).

Por lo tanto, los rasgos que son recogidos en la escritura han pasado por el tamiz del autor, que actúa como primer filtro, de modo que la selección que él haga dependerá de su sensibilidad como hablante nativo de la lengua en la que escribe, de su nivel de cultura en cuanto al registro normativo del idioma y de las convenciones gráficas de las que disponga dicha lengua. Además, por tratarse de un recurso escritural, responde al plan de escritura del autor (Ruiz Velasco 2016: 301) y, por lo tanto, constituye parte de su estrategia.

Considerando lo anterior, y partiendo de la idea de Fuentes González (2017: 106) de que "todo texto (también el literario) es susceptible de lecturas sociolingüísticas, en tanto que conjunto de prácticas lectoras orientadas a desentrañar realidades y procesos sociales desde los que todo texto se produce, se recibe y se interpreta", el objetivo de este artículo es analizar un conjunto de dos textos inéditos de temática campesina, escritos por el dramaturgo, director y actor chileno Roberto Navarrete, entre los años 1963 y 1970, rastreando en ellos los distintos fenómenos fónicos, léxicos y morfosintácticos con los que reconstruye el habla de sus personajes rurales para, finalmente, proponer una interpretación del uso que hace el autor de este recurso.

En el apartado 2, se encontrará una breve biografía del dramaturgo y del argumento de cada una de las obras analizadas. En el 3, se analizarán y ejemplificarán los recursos de oralidad fingida utilizados en los textos, para, finalmente en el acápite 4, ofrecer al lector una interpretación global del uso de estos recursos. 


\section{EL DRAMATURGO Y LAS OBRAS}

\subsection{ROBERTO NAVARRETE}

Roberto Navarrete Troncoso (1925 - 1999) fue un actor, director y dramaturgo oriundo de Bulnes, comuna rural ubicada en la actual Región de Ñuble. En 1952, ingresa como actor al Teatro de la Universidad de Concepción (TUC), el cual dirigió en varias oportunidades, a partir de 1955 (Contreras, Henríquez y Albornoz 2003). En la Universidad de Concepción, fue jefe del desaparecido Departamento de Teatro.

Publicó en 1987 el libro Los herederos de las moscas, en el cual aparecen tres de sus obras, las únicas publicadas hasta ahora: Los herederos de las moscas, Carta abierta a individuos no identificados y Hora cero. Sin embargo, su labor dramatúrgica no acaba con ellas. Anteriormente, había escrito Su día gris, El cochayuyero, La mariposa en el barbecho, Navidad en la aldea, La flor de la laguna, entre otras.

Como actor, además de los variados roles interpretados al alero del TUC, tuvo apariciones en cine, específicamente, en películas emblemáticas de la producción nacional, como Estado de sitio, de Costa Gravas; El chacal de Nahueltoro, de Miguel Littin, y Ya no basta con rezar, de Aldo Francia. También actuó en telenovelas, tales como La gran mentira, La dama del balcón, La torre 10, Adrenalina, entre otras (Cf. Navarrete 1987; "Murió actor chileno", 1999).

A continuación, se ofrecen brevemente los argumentos de las dos obras inéditas de temática campesina analizadas, con algunos datos relevantes de su creación o estreno.

\subsection{EL COCHAYUYERO ${ }^{3}$}

Fue creada en 1963. Se estrenó en 1965, en la Escuela de Odontología (hoy Facultad de Odontología) de la Universidad de Concepción, con estudiantes de la misma escuela, bajo la dirección de Inés Fierro, esposa del dramaturgo, que, en la época, se desempeñaba como académica de dicha repartición.

El conflicto se centra en el desalojo de Rosendo de la puebla que ocupa con su familia, acto ejecutado por el mayordomo y sus capataces, enviados

3 De ahora en adelante, esta obra será identificada en este artículo como COCH. 
por el nuevo patrón. El cochayuyero, hombre humilde pero letrado, llega a escena en el momento en que Juan, hijo analfabeto de Rosendo, descansa en una vertiente. Entre ambos, ayudados por Estanislao -un vendedor viajero- llevan el caballo enfermo del cochayuyero a la casa de Rosendo para que lo vea y lo cure. Mientras están en la vertiente y, luego, en casa de Rosendo, hacen su aparición Mercedes y su hija Flor -enamorada de Juan-, quienes iban a pagar una manda a San Sebastián, en Yumbel. Hasta ese lugar concurren también el mayordomo y los capataces, quienes sacan violentamente a Rosendo de su casa, desatan el cargamento de cochayuyos y entregan a la policía al cochayuyero y a Estanislao. En un acto de dignidad, Juan recoge los atados de algas secas y promete venderlos, para llevar el dinero a la casa del cochayuyero. Por último, Juan manifiesta su deseo imperioso de aprender a leer.

\subsection{LA MARIPOSA EN EL BARBECHO ${ }^{4}$}

Fue estrenada en 1969 por el TUC, bajo la dirección del mismo Roberto Navarrete.

Aquí el conflicto amoroso es un pretexto para visibilizar el contraste entre la decadencia moral de la clase patronal y la dignidad humana de los peones, oposición que se hace patente en la legitimización fallida de una relación amorosa entre la hija del patrón y un peón itinerante: Luis, invitado por Amadeo, ingresa a trabajar en la hacienda de Tristán. Allí comienza un amorío con Ester, la hija del patrón, la que, a la vez, está de novia con Jorge. Luis y Ester planean fugarse juntos, pero Jorge los descubre y deja expuesta la índole promiscua de Ester, frente a lo cual Luis la desprecia a ella y a Jorge.

Los personajes de estos textos representan distintos tipos campesinos: el patrón (Tristán en MEB), el inquilino (Rosendo en $\mathrm{COCH}$; Amadeo en MEB), el afuerino (Cochayuyero en $\mathrm{COCH}$ ), el peón itinerante (Luis en MEB), la esposa del inquilino (Margarita y Juana en MEB; Mercedes y Flor en $\mathrm{COCH}$ ), la hija del patrón (Ester en MEB), el futre (Jorge en MEB), el borracho (Bartolo en MEB), el capataz. Por ello, el habla campesina recreada en estas dos obras de Navarrete remite a formas estereotipadas y rememoradas de concebir la ruralidad, pues el propio autor tuvo la experiencia vital del campo, ya que nació y creció allí.

4 De ahora en adelante, esta obra será identificada en este artículo como MEB. 


\section{LOS RECURSOS DE ORALIDAD SIMULADA}

En la dramaturgia nacional, la inclusión de hablas rurales o de grupos sociales determinados no es novedad. A inicios del siglo XX, Acevedo Hernández, harto de los personajes altisonantes del teatro europeo o clásico, comienza a emplear en sus creaciones dramáticas el lenguaje del pueblo. En efecto, en la reseña que hace Juan Andrés Piña de la obra Chañarcillo, Antonio Acevedo Hernández afirma: "En las obras que veía diariamente aparecían demasiados marqueses, condes, duques, duquesas y hasta reyes y reinas. Creí que el pueblo chileno, nunca utilizado por los autores novicios, me entendería, sentiría su propio dolor, que también era el mío..." (Piña 1990: 126). Como se observa, su finalidad no solo es mimética, en el sentido de querer representar la realidad de sectores bajos u obreros de la sociedad chilena de la época, sino, sobre todo, catártica: quería que el pueblo sintiera "su propio dolor" (Ibidem).

Algo similar a la experiencia de Acevedo Hernández ocurre en obras paralelas y también en otras de décadas posteriores: La viuda de Apablaza, de Germán Luco Cruchaga, estrenada en 1928; en la década del 50 en obras como Mama Rosa, de Francisco Debesa y Ánimas de día claro, de Alejandro Sieveking; o en los 80, en Décimas de la Negra Ester, de Roberto Parra, llevada al teatro por Andrés Pérez, en 1988; y en muchas otras obras de la década del $90^{5}$. En otras propuestas, la representación de habla de un grupo social no responde más que a un recurso estético de ambientación, por lo que el autor recurre más bien a estereotipos aceptables, como ocurre con Entre gallos y media noche, estrenada en 1919 (Cariola 1920). De todos modos, en ambos casos, en la representación con finalidad catártica y en la representación estereotipada del habla, aparecen recursos de oralidad fingida muy similares.

De las obras de Navarrete que aquí se analizan, se puede decir que el autor "naturaliza formas lingüísticas anómicas, sin apenas marcas gráficas enfáticas" (Fuentes González 2017: 107). En sus textos, algunas expresiones lingüísticas están entrecomilladas, lo que se puede interpretar como una forma de dar a entender que el autor tiene conciencia de que se trata de formas propias de un registro específico. Con todo-y como ya se dijo- los recursos

5 Para una antología de obras estrenadas en los 90 y en décadas posteriores, véase Hurtado y Barría (2010). 
utilizados en la escritura son siempre una selección proporcionada por el autor, basada en sus percepciones y experiencias como usuario de la lengua.

Bajo la óptica de lo precedente, en los apartados siguientes se presentan y ejemplifican los principales recursos de oralidad simulada que aparecen en las obras analizadas.

\subsection{RECURSOS FÓNICOS}

Los recursos fónicos ${ }^{6}$ constituyen la clase con mayor presencia en los textos teatrales que intentan reproducir el habla de un grupo social determinado. Los textos de Navarrete no son la excepción. En efecto, tanto en $\mathrm{COCH}$ como en MEB se encuentran algunos casos de elisiones de sonidos ${ }^{7}$ : a) aféresis, principalmente del verbo estar: ahí tá 'ahí está', tará de Dios 'estará de Dios'; pero también en onde 'donde'; b) síncopas, vocálicas (custión 'cuestión') y consonánticas, algunas de ellas bastante extendidas en el español de Chile: elisión de /d/ entre vocales (baulaque 'badulaque', pescao 'pescado', empalao 'empalado', ataito 'atadito', vía 'vida'), algunas veces con contracción vocálica (adecuá 'adecuada', botá 'botada', cortás 'cortadas'); elisión de /g/ (mure por 'mugre'). Singular es la síncopa del grupo $m b$ en la palabra taién 'también'; c) apócopes, sobre todo los más extendidos en el habla coloquial: $p a$ ' 'para' (Poblete, Pons y Samaniego, 2000) y $n a$ ' 'nada', y la pérdida de la /d/ final de palabra, como en fatalidá 'fatalidad'; d) contracciones, de las cuales aparecen unos pocos casos de contracción de sintagmas, producto de sucesivos procesos fónicos: sinalefa, posterior diptongación y cambio vocálico en quiubo 'iqué hubo!', usada como saludo informal, y en diadonde 'de adónde'; apócope y aféresis en pa 'cá 'para acá' y en $p a$ ' $l$ 'para el'; y sinalefa y síncopa en estora 'esta hora'.

Existen también otros fenómenos fónicos que se destacan, como cambios vocálicos que facilitan diptongos (e $>$ i: tranquear $>$ tranquiar; de adonde $>$ diadonde), prótesis de /g/ en el diptongo creciente /ue/ (güeno) (cf. Sáez, 1999), disimilación de zona de articulación (fuerte $>$ juerte), fluctuación de fonemas líquidos en posición de coda silábica (percherona $>$ pelcherona).

\footnotetext{
6 Para los procesos fónicos, se tomó como referencia el texto de Alba (1998), mientras que, para el habla chilena, se usaron los trabajos de Rabanales (2000), Pérez (2007), SotoBarba (2011) y Soto-Barba, Díaz y Pereira (2015).

En la explicación de los fenómenos fónicos, se usará la barra oblicua, propia de la transcripción fonológica, en el entendido de que el dramaturgo intenta reproducir sistematizaciones de lo oral rural.
} 
Un caso de acumulación de transformaciones fónicas es la palabra ifariar 'desvariar', en la que se elide la consonante inicial y se simplifica la secuencia /sb/ por/f/.

Por último, se presenta el caso de auciones 'acciones', en el que $/ \mathrm{k} /$ pierde valor consonántico por su posición en coda y se vocaliza en $/ \mathrm{u} /$.

\subsection{RECURSOS LÉXICOS}

\subsubsection{Términos vernáculos}

Según Rabanales (2000: 138), "aquello en que más repara un hablante cuando quiere caracterizar su lengua, es en el vocabulario". Por ello, no extraña que entre los recursos léxicos ${ }^{8}$ a los cuales recurre Navarrete destaca el uso de términos propios del ámbito campesino, específicamente, del sistema de inquilinaje y de las labores asociadas como, por ejemplo, puebla 'lugar de residencia del inquilino y huerta asociada', rebenque 'látigo', quisca 'cuchillo, puñal', chinchel 'taberna'; o a formas de tratamiento formal o coloquial, como iñor 'señor', on 'don', güeñi 'joven, niño', coltro ${ }^{10}$ 'niño, hijo', guaina 'joven', taita o taitita 'padre, papito' y chicuelo. Otros vocablos se relacionan con cualidades, positivas o negativas de personas, como ayecahue 'gracioso, alocado', alentá (alentada) 'atenta, servicial', además de 'bien de salud, saludable'; adecuá (adecuada) 'de comportamiento correcto o esperable', zoronda 'despreocupada', condolío (condolido) 'compasivo', enredosa 'chismosa', alvertio (advertido) 'capaz, experto', cachúo (cachudo) 'desconfiado', hambriá (hambriada) 'con mucha hambre', templá (templada) 'enamorada', baulaque (badulaque) 'pícaro, canalla'. También utiliza

8 Los significados de las palabras mencionadas se han extraído del Diccionario de la Lengua Española (RAE y ASALE 2014), del Diccionario araucano (Augusta 2007), del Diccionario de americanismos (ASALE 2010), del Diccionario de chilenismos (Grass 1993), del texto de Meyer Rusca (1952), del Diccionario ejemplificado de chilenismos (Morales, Quiroz y Peña 1984, 1985, 1986; y Morales Quiroz, Riffo y Copello 1987), del Diccionario etimolójico (Lenz 1910) y de diversas consultas a hablantes de zonas rurales. Para algunos términos se han adaptado los significados de acuerdo a lo que quieren decir en las obras analizadas.

9 Como indica Oroz (1966: 293), se trata de abreviaciones de las palabras respectivas.

10 Existen dudas del origen mapuche de esta palabra (Morales et al. 1985). De acuerdo con Lenz (1910: 202-203), se trata de una raíz con bulbos comestibles. Tal vez el significado de niño o hijo se deba a una comparación con esta planta. También es posible que proceda de koltrau, voz mapuche que significa 'renacuajo' (Augusta 2007). 
verbos poco frecuentes en el habla urbana o con significados diversos a los normativos, como echar una meucaita (de meucar ${ }^{11}$ ) 'cabecear', entumirse 'inmovilizarse a causa del frío', encaracharse 'mostrar mala cara a alguien; oponerse a alguien', cargosear 'molestar', escarmentar 'aprender de la propia experiencia', arrebatarse 'calentarse bebiendo alcohol; emborracharse', mancornarse 'emparejarse', fundirse 'malgastar algo, especialmente, el dinero', arrebosar 'llenar un recipiente hasta que rebose'. Destaca también la incorporación de dos interjecciones: idiay o diay ${ }^{12}$, que se usa en el texto para expresar diversos actos de habla, tales como 'afirmación', 'desconocimiento' o 'admiración', y benaiga, la que forma parte inicial de unos versos que canta Estanislao en $\mathrm{COCH}$, como forma de expresar malestar o queja. Por último, Navarrete entrecomilla en su escritura algunas palabras que, a su juicio, son propias de sus personajes rurales: cachivache 'cosa inservible, en sentido despectivo', pobrería 'conjunto de personas pobres', guaracazo 'golpe y sonido fuertes; bombazo', boquillazo 'alocución breve que causa molestia o enojo; reprimenda', burrá (burrada) 'dicho o hecho tonto', gabela 'impuesto', pencacito (de pencazo) 'trago largo de alcohol', saranguaco (o saranhuaco) 'mezcolanza ${ }^{13}$, asentaderas 'nalgas', tolondrón 'chichón', bolina 'asunto', tarasca 'boca grande', cuntrita (de cutra) 'bota de cuero o cámara de neumático usada para trasladar aguardiente ${ }^{14}$ y patentito (de patente), usado en el texto como adverbio con el significado de 'claramente'. Sin duda, algunos de estos vocablos resultarán habituales para el lector de hoy, mientras que otros los sentirá como ajenos, lo que demuestra, en cierta medida, el flujo continuo de las expresiones y el cambio de estatus que sufren a lo largo del tiempo.

11 Según Morales et al. (1986), se trata de un mapuchismo.

12 Se trata de una "alteración fonético gráfica de ¡y de ahí! con alteración semántica" (Morales et al. 1986).

13 En el Morales et al. (1987), saranhuaco se caracteriza como una palabra nortina, definida como "cierta vianda, similar al ceviche...". Sin embargo, en el texto de Navarrete se usa con el sentido de 'mezcolanza', a semejanza de lo que propone Rodríguez (1999), en relación con un poema de Nicanor Parra que tiene esta palabra como título. Su etimología no es clara.

14 En MEB, Navarrete escribe cuntrita, lo que parece ser un lapsus calami para lo que debería ser cutrita. Tanto en Morales et al. (1984) como en Pescador (2011), la palabra remite al traslado del aguardiente, pero difieren en su material de confección: en el primero se menciona la tripa de un animal, mientras que en el segundo se especifica que es la cámara de goma de un neumático. Se trata de un mapuchismo. 


\subsubsection{Expresiones idiomáticas}

Otro recurso léxico del cual hace uso Navarrete en sus obras es la incorporación de unidades fraseológicas propias del habla chilena. Al igual que con los vocablos de la sección anterior, se han analizado aquí las expresiones que el mismo autor considera "especiales", razón por la que las escribe entre comillas:

\section{Roto gallo}

[Acotador] Estanislao Tejas es un hombre de aproximadamente 50 años, de gran agilidad física, "Roto gallo". Saluda en general $(\mathrm{COCH})$

Esta expresión aparece en $\mathrm{COCH}$ y refiere a un vendedor ambulante con ideales políticos, un agitador. La expresión combina los elementos roto, personaje propio del pueblo, y la adjetivación gallo, que se refiere a un hombre "altivo, audaz que se atreve a enfrentar con éxito situaciones peligrosas o difíciles" (Valencia 2010: 599). Lo interesante de esta expresión es que aparece en el discurso del acotador, no en las intervenciones de los personajes.

\section{¿Cómo anda el bolo? / Da güelta solo}

Juan ¿Qué dice, don Estanislao?... ¿“Como anda el bolo”...?

Estanislao "Da güelta solo", pus. (Pausa) Aquí andamos, pus, "güeñi”, rajuñando para poder vivir. $(\mathrm{COCH})$

Como se observa, se trata de una fórmula de saludo completa. No se halla registrada en los diccionarios de chilenismos, pero su función de apertura de canal comunicativo es evidente.

Buscar el "agua de la vía"

Mercedes (Entrando) Güenas tardes (Flor va hacia ella). Buena sos vos para mandarte a buscar el "agua de la vía”, ¿no? (COCH)

No fue posible dar con la definición de esta expresión en los diccionarios. Parece que el destacado hecho por el autor fue motivado por una hipérbole irónica: Flor se demora tanto en ir por agua a la fuente que, si hubiere tenido que ir por el agua que da la vida, la persona que la necesitare ya habría muerto. 


\section{Del guán}

Estanislao Usted, señorita... mire qué pañuelo más bonito... ¡del "guán"!... Son dos mil pesos no más... ¡Tome, es suyo! $(\mathrm{COCH})$

La expresión procede de la palabra one 'uno' en inglés, castellanizada en su pronunciación, en su ortografía y en su sintaxis. Quiere decir en el contexto 'de primera calidad, muy bueno'.

No cierto

Amadeo Salió... A ver, acérquese pa'cá. (Se acerca maliciosa con toda su exuberancia)

Juanita ¿Y para qué?

Amadeo le pega un atrincón delante de don Quicho. Este no reacciona, mira para el lado.

Juanita Don Quicho no es na celoso, ¿no cierto? (MEB)

Esta expresión es una variante del marcador no es cierto, que suele ir acompañado de entonación interrogativa y, como en el caso citado, tiene un valor confirmativo o de aprobación a lo dicho anteriormente (Pons y Samaniego 1998), aun cuando en otros contextos pueda ser solo un marcador de control de contacto (San Martín 2011). Es interesante notar que en la investigación de Pons y Samaniego (1998) se sitúa este marcador entre los representativos del grupo etario superior a los 56 años y en la de San Martín (2011), en el grupo superior a los 35 años, lo cual valida su uso en personajes adultos de un texto escrito el año 1969.

\section{Domingo siete}

Estanislao Acuérdese que yo soy soltero, doña Mercedes.

Mercedes Sí... soltero, pero con su "domingo siete". (COCH)

Aunque tanto en ASALE (2010) como en Morales et al. (1984) aparece esta expresión con la acepción de 'dicho o hecho inesperado', en el texto quiere decir 'hijo nacido fuera del matrimonio' (Lagos, Castro, Lee, Miranda y Ramos 2005). 
Quedar pa'las calendas

Mercedes Ahí donde la Chela quedó. (Salen) ¡Qué barbaridad más grande, Díos mío! Si el pobre no puede hacer ningún plan... too sale mal. (A Estanislao) Se encontró con el tal Vitorino, que cuando esa bestia se cura, es peor que lapa... Le empezó a exigir a Marcos y aonde a este lo pilló débil, en poquito rato quedó "pa' las calendas", sin poder dar un tranco. ¡Qué me dice usted...! ¡Había visto fatalidá más grande...! ¡Es para sacarse ejemplo, no...! ( $\mathrm{COCH})$

El sentido de la expresión sugerido por el texto es 'emborracharse hasta el límite', pero no es totalmente claro. Quedar para las calendas no aparece en ninguno de los textos consultados, aún más cuando el término calendas hace referencia a un periodo de tiempo y no a un estado de conciencia, ni siquiera en sentido metafórico. Tal vez se trate de una locución idiosincrásica del autor, sin repercusión social posterior.

\section{Parar la olla}

Amadeo Así es la cosa, pues, amigo: el pez más grande se come al más chico. Mire, usted, empecé a trabajar de "guainita" y después de treinta años, apenas me alcanza "pa' parar la olla"... Patiperrié harto sí; rebuscándola, llegué hasta la Patagonia. Casi me cagué de frío, así es que me las "emplumé" de vuelta... después 'tuve en El Teniente, ahí sí que se ganaba plata, no ve que eso es de los gringos... (MEB)

De acuerdo con ASALE (2010), esta expresión quiere decir "ganarse el sustento diario realizando cualquier actividad lucrativa".

\section{Emplumárselas}

Término presente en el fragmento anterior que significa 'fugarse, huir de algún riesgo o compromiso'. (ASALE 2010).

Ser la piedra de tope

Amadeo (...) Oye... ¿Voy a ver si el patrón le da trabajo a este cabro?

Margarita ¡Metete en líos, no más... como yo soy la piedra de tope! (MEB) 
Este chilenismo, no destacado entre comillas por el autor, se define en ASALE (2010) como una "cosa que impide realizar algo". Sin embargo, en el texto de Navarrete es Margarita, la mujer de Amadeo, quien se refiere a sí misma con esta locución, de modo que su significado parece ser el de "persona a quien recurren las demás en busca de auxilio o amparo" (Morales et al. 1987: 3596).

No reventársele la hiel a alguien

Amadeo Pasa pa' adentro y saluda, pu, burro (Saludo en gestos. Sirviéndole un vaso) Toma... "pa' que no se te reviente la hiel". (MEB)

Para Morales et al. (1986: 2318), se trata de una locución verbal de significado restringido al "acto de saborear un manjar". En la tradición popular, cuando una persona está comiendo algo frente a otro, al menos debe darle a probar, pues, si no lo hace, puede 'reventársele la hiel' y, en consecuencia, enfermar o morir.

\section{Otro gallo cantaría}

Margarita Bueno, y qué le digo yo... (Pausa) Lo único que faltaba..., a mí retándome la niña. Estoy segura de que si la señora supiera esto "otro gallo cantaría". (Pausa) Pero Amadeo es el que tiene toda la culpa. (Pausa) Tan "condolío" que lo han de ver. (Pausa) Pero me las va a pagar carito sí... (MEB)

Es una expresión común en el habla chilena. Significa "suceder algo muy distinto o contrapuesto a lo que estaba sucediendo en similares circunstancias" (Morales et al. 1985: 2145).

Tan ... que lo han de ver

La expresión está asociada en el fragmento anterior al adjetivo condolido. Se trata de una frase exclamativa de carácter ponderativo para realzar, de manera irónica, una cualidad (Morales et al. 1987).

No dejante

Amadeo ¡Ya, cállate, hombre! "No dejante" todas las preocupaciones que uno tiene y ahora salís vos... (Bartolo permanece mudo) ¿Qué, te tragaste la lengua? (MEB) 
Expresión propiamente campesina que, como señalan Morales et al. (1985), adopta en el texto el significado de un marcador aditivo, equivalente a 'fuera de que' o 'además de'.

\section{Estar hasta las masas}

Cristóbal Ya lo quisiera ver yo... tengo cada "tolondrón".

Amadeo "Ta hasta las masas", entonces, compadrito. (Pausa) Aproveche de rebelarse ahora... Déjeme a mí, iyo le voy a largar la pedía! (MEB)

La locución, con verbo estar, no se halla registrada en los diccionarios, pero sí la expresión las masas, una de cuyas acepciones, con verbo tener y regida con la preposición hasta, parece ser la adecuada para este contexto: la 'cúspide' de algo o de una situación (Morales et al. 1986: 2854). Por lo tanto, estar hasta las masas sería 'sentirse en el límite, en lo máximo de una situación, con sentido negativo'.

\section{Hacérsele a uno la pajarilla}

Estanislao Como todo sale en la conversación del pobre, yo también fui hombre de mar donde usted me ve; fui managua y me echaron pa' la revuelta del '31. ¡Pa'qué le cuento lo duro que lo pasé! 'Taba en uno de los buques surtos en la bahía de Talcahuano dele "guaracazo" pa' los cerros sin pararle. Era una verdadera lluvia de balas, a mí me hacía así la pajarilla. $\mathrm{Y}$ ahora me tiene vendiendo cachivaches. $(\mathrm{COCH})$

No hay registros de esta expresión en los diccionarios consultados. Sin embargo, pareciera que está vinculada con el hígado o el bazo -de hecho, en el RAE y ASALE (2014) se registra como tal- y de ahí con la palabra pana $^{15}$, en la locución tener pana 'tener valor' (Meyer Rusca 1952; Grass 1993). Por lo tanto, hacérsele a uno la pajarilla vendría ser 'sentir miedo', como en la expresión castellana hacer temblar la pajarilla a alguien, con el sentido de 'causar temor' (RAE Y ASALE 2014). También la palabra pajarilla podría guardar relación con el órgano sexual masculino o femenino

\footnotetext{
De acuerdo con Meyer Rusca (1952), pana es una palabra mapuche que significa 'hígado'.
} 
(ASALE 2010), según el caso, pero esto no implicaría otro nuevo significado de la expresión más que el ya propuesto.

\subsection{MorfosintaXis ${ }^{16}$}

\subsubsection{Variación morfológica de nos}

La secuencia los vamos, destacada en el fragmento, rescata el uso del pronombre personal de tercera persona plural los por el de primera nos.

Mayordomo (...) Te vas a mandar a cambiar altiro y no quiero verte más por aquí. $\mathrm{O}$ en la noche los vamos a arreglar de otra manera, oye... $(\mathrm{COCH})$

Este cambio de persona está propiciado por el punto de articulación alveolar, común a ambas consonantes iniciales de los pronombres respectivos. A pesar de esta motivación fónica, el fenómeno es considerado por RAE y ASALE (2009: 1166) como "variantes morfológicas (...) [que se dan] en el habla rural de algunas regiones de Chile, la Argentina, el Uruguay (...)", razón por la que se presenta en este apartado de morfosintaxis. Interesante es también destacar que, en el español de Chile, la neutralización de /1/ y $/ \mathrm{n} /$ se ha descrito como común para posición implosiva (v.gr.falda $\sim$ farda), pero no para posición de inicio de sílaba (Cartagena 2002).

El uso de los por nos solo aparece atestiguado en $\mathrm{COCH}$, donde es sistemática su presencia. No se registran casos de losotros por nosotros, fenómeno relacionado con el anterior (RAE y ASALE 2009).

En la actualidad, se observa a priori un avance de este uso hacia otros estratos del dialecto chileno, sobre todo al habla de estratos urbanos de condición socioeconómica baja.

\subsubsection{Voseo}

En las obras de Navarrete analizadas, el voseo aparece ampliamente y bajo diversas manifestaciones, reflejando la compleja e inestable situación que este fenómeno posee en la lengua (Sáez 1999; Poblete, Pons y Samaniego 2000; Cartagena 2002; RAE y ASALE 2009). De acuerdo con la clasificación

16 En esta sección, se escriben en negrita las secuencias que se están comentando. 
que se hace en RAE y ASALE (2009: 1261), se pueden distinguir tres clases de voseo, a saber: voseo flexivo pronominal, en el que coocurren las antiguas desinencias verbales de plural con valor de singular y el pronombre vos; voseo flexivo no pronominal, que mantiene el uso de las desinencias, pero carece de la presencia del pronombre vos, aun cuando pudiera aparecer tú; y el voseo no flexivo pronominal, es decir, el uso del pronombre vos con formas flexivas propias de la segunda persona singular. En los textos de Navarrete se dan los tres tipos, como se puede observar en los ejemplos siguientes:

\section{Voseo flexivo pronominal}

Flor Esta otra semana me van a llevar pa' Santiago los patrones.

Juan ¿Para qué?

Flor Para trabajar en la casa de ellos allá.

Juan ¿Y vos querís irte?

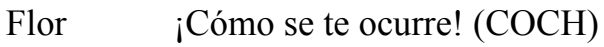

\section{Voseo flexivo no pronominal}

Mercedes (A Flor) Y vos que te lo pasás moquiando no más (Mirando con simpatía a Juan). Te hacís el mojigato, bribón, y tenís toda la culpa de que mi chiquilla llore. $(\mathrm{COCH})$

Nótese en este ejemplo que el personaje utiliza primero el voseo flexivo pronominal ("Y vos te lo pasás moquiando") y, a continuación, el voseo flexivo no pronominal, con uso de pronombre átono segunda singular ("te hacís el mojigato") y, finalmente, sin pronombre ("tenís toda la culpa de que mi chiquilla llore").

\section{Voseo no flexivo pronominal}

Estanislao (...) Oye, tu papá me encargó que le trajera unos paquetitos de vela... ¿Se los podrías llevar vos...? ¿Vas para allá? $(\mathrm{COCH})$

Es interesante notar que, en las obras de Navarrete, el voseo -en cualquiera de sus manifestaciones- es un fenómeno que marca la identidad popular común de los personajes campesinos, pues ninguno de los personajes de mayor rango social lo usa. Esto refrenda lo indicado por Oroz (1966: 296), quien afirma que el voseo es "predominante en las clases populares urbanas y entre los campesinos y mineros". 


\subsubsection{El sufijo -azo}

Oroz (1966: 286) describe este sufijo como un aumentativo que pondera tamaño o cantidad y que es propio de "la gente del bajo pueblo". En el ejemplo que sigue, el adverbio lejos es ponderado en su cantidad:

Cochayuyero (Sonriendo) Yo soy de lejazos. ¡Buh!, hay andao harto (Pausa). Vengo de Cobquecura. $(\mathrm{COCH})$

También Oroz (1966) indica que el sufijo - azo puede significar 'golpe o acción', como se observa en el caso siguiente:

Mayordomo (Más violento) Y no te "encarachís" na' mejor... mira que te agarro a rebencazos... $(\mathrm{COCH})$

\subsubsection{Plurales irregulares}

Solo se detectó un único caso en las obras analizadas. Se trata de la forma jabalises, plural de jabalí, que aparece en MEB.

Amadeo (Mirándole la lengua) A ver, tiene la lengua blanquita... ¿No tendrá fiebre?

Jorge No... si no es nada, hombre.

Amadeo ¿Y cómo a mí me contaron que estaba viendo hasta “jabalises”, iñor? (MEB)

De acuerdo a la regla, "los sustantivos y adjetivos acabados en $-i$ tónica tienden a admitir las dos variantes de plural: $-e s$ y $-s$ " (RAE y ASALE 2009: 132). Sin embargo, se indica a continuación que algunos sustantivos, como maravedi y maní, admiten una tercera forma, no recomendada: maravedises y manises, respectivamente, es decir, se construye el plural con una combinación de morfos. Este es el caso que aparece en MEB.

\subsubsection{Fenómenos asociados al verbo haber}

El primero de los casos, corresponde a la construcción impersonal de haber existencial; el segundo, al uso de haber como auxiliar de tiempos compuestos.

\subsubsection{Personalización de haber existencial}

Se detectó solo una forma en las obras analizadas, específicamente en $\mathrm{COCH}$. El fenómeno consiste en interpretar el complemento directo de haber como 
sujeto léxico, lo que se ve reflejado en la concordancia de número entre el complemento y el verbo.

Cochayuyero Es grandazo este fundo....ah.

Juan

Sí. Debe de tener unas... mil hectáreas tendrá, pues. Habimos como doscientos inquilinos. (Pausa) Hay buenas chacras, viñas, lecherías, es tierra muy güenaza esta, como pocas por aquí... ( $\mathrm{COCH})$

En el ejemplo, doscientos inquilinos es el completo directo de habimos, que recalifica como sujeto: de ahí el plural.

De acuerdo con Oroz (1966), la personalización de haber existencial está presente en todo el país, incluso en hablantes cultos. Sáez (1999) y Cartagena (2002) aseguran que este uso está en proceso de generalización.

\subsubsection{Uso arcaico de haber}

Oroz (1966) indica que la forma hay para la primera persona singular del presente de indicativo de haber -usada en $\mathrm{COCH}$ de manera amplia- se halla extendida en gran parte de los sectores campesinos del país. Se considera más rural que la arcaica hey -no presente en los textos de Navarrete, forma que en la actualidad se usa con la variante apocopada he (RAE y ASALE 2009: 247). A continuación, un ejemplo:

Rosendo (...) Yo hay sio toa mi vida un hombre de trabajo. Usted me conoce, don Estanislao... (COCH)

\section{UNA POSIBLE CONCLUSIÓN}

Como se puede observar en los apartados precedentes, en las dos obras descritas existe abundancia de recursos sociolingüísticos que evidencian un habla chilena campesina. Esta inclusión de palabras, expresiones y formas verbales propias del habla rural puede interpretarse como una herramienta lingüística de "descolonización cultural" (Lienhard 1994:372), un procedimiento mediante el cual los protagonistas reivindican lo campesino y lo sitúan en el centro de interés del drama. Por ello, la escritura de Navarrete deviene en oralizante, en los términos de Lienhard (1994), ya que utiliza recursos para crear, en las obras analizadas, un sentido político-cultural que 
reproduce el "discurso oral de los marginados" (Lienhard 1994: 374), de los oprimidos: el del inquilino desechado por sus patrones (Rosendo en $\mathrm{COCH}$ ), el del silenciamiento temeroso y horrorizado de la esposa del inquilino frente a la inmoralidad de sus patrones (Margarita en MEB), el de la resignada empleada que debe abandonar sus proyectos personales para seguir a sus jefes a otros horizontes (Flor en $\mathrm{COCH}$ ); el del hijo analfabeto, impotente ante la prepotencia de los poderosos (Juan en COCH).

En los textos analizados, más que utilizar el habla campesina como simple recurso estético, Navarrete parece querer transcribirla. Por eso su escritura abunda en recursos fónicos, léxicos y morfosintácticos, lo que la convierte a momentos en 'extraña' para el lector en cuanto texto escrito, pues con los materiales que de ella dispone intenta reproducir lo más fielmente posible los fenómenos orales característicos de esta variante sociolectal. En este sentido, estos textos de Navarrete son portadores de rasgos propios de la ruralidad que intenta recrear, razón por la cual se puede afirmar que se trata de textos permeados por lo oral, por cuanto son capaces de "expresar la sociedad y la cultura de la cual emana[n]" (Gallardo 2001: 97).

Aventurando una posible interpretación, es lícito decir que los recursos lingüísticos de oralidad fingida o simulada servirían como medio para expresar un procedimiento de recentralización de lo campesino, sin que ello implique una descentralización de lo urbano. De hecho, en su época de escritura, Navarrete rompió en cierta medida la tradición del TUC de representar obras extranjeras en lenguaje estándar, presentando una dramaturgia local con un lenguaje propio ${ }^{17}$. Ese fue su principal aporte al teatro nacional.

\section{REFERENCIAS BIBLIOGRÁFICAS}

Alba, Orlando. 1998. Los sonidos del español. Santo Domingo: Librería La Trinitaria. Asociación de Academias de la Lengua Española (ASAle). 2010. Diccionario de americanismos. Lima: Santillana Ediciones Generales.

17 Navarrete comienza su carrera actoral en el TUC el año 1952, pero asume oficialmente como director el año 1964. Hasta entonces, el TUC había representado solo 7 obras nacionales (El ensayo de la comedia, de Daniel Barros Grez; Dos más dos son cinco, de Isidora Aguirre; Población esperanza, de Manuel Rojas e Isidora Aguirre; Las redes del mar, de José Chesta; La niña madre, de Egon Wolff; Entre gallos y medianoche, de Carlos Cariola; y Su día gris, de Roberto Navarrete), mientras que el resto del repertorio estrenado corresponde a autores europeos, norteamericanos y unos pocos latinoamericanos. (Cf. Contreras et al. 2003). 
Augusta, Felix José De. 2007. Diccionario araucano. Mapuche-español, español-mapuche ( $4^{\mathrm{a}}$ ed.). Santiago de Chile: Ediciones Cerro Manquehue.

CARIola, Carlos. 1920. Entre gallos y media noche. Sainete criollo vaudevillesco en 3 actos. Santiago de Chile: Librería Hémette y Frías.

Cartagena, Nelson. 2002. Apuntes para la historia del español en Chile. Santiago de Chile: Cuadernos de la Academia Chilena de la Lengua.

Contreras, Marta, Patricia Henríquez y Adolfo Albornoz. 2003. Historias del Teatro de la Universidad de Concepción: TUC. Concepción: Trama.

Debesa, Fernando. 1969. Mama Rosa. Santiago de Chile: Universitaria.

Eberenz, Rolf. 2001. Diálogo y oralidad en la narrativa hispánica moderna. Perspectivas literarias y lingüisticas. Madrid: Verbum.

FueNTES GonZÁLEZ, ANTONIO. 2017. Integración sociolingüística de paisaje y paisanaje en $E l$ barranco de los gitanos, de Fernando Robles. Analecta Malacitana Electrónica 42: 104122 [en línea]. Disponible en https://dialnet.unirioja.es/descarga/articulo/6058287.pdf.

Gallardo, AndRÉs. 2001. La lógica de la oralidad. Aisthesis 34: 92-100 [en línea]. Disponible en http://revistaaisthesis.uc.cl/index.php/rait/article/view/982/930.

Grass, Jacobo. 1993. Diccionario de chilenismos (2 ${ }^{\mathrm{a}}$ ed.). Santiago de Chile: Pax.

Hurtado, María de la Luz y Mauricio Barría (Comp. y eds.). 2010. Antología: Un Siglo de Dramaturgia Chilena. 1910-2010 (Tomo IV: 1990-2009). Santiago de Chile: Bicentenario.

Lagos Altamirano, Daniel; Andrés Castro Figueroa; Nathan Lee Joiner; Victoria Miranda EsPinOza y Rodrigo Ramos Riveros. 2005. Diccionario lingüistico del habla de Valparaíso. Valparaíso: Universidad de Playa Ancha de Ciencias de la Educación.

Lenz, Rodolfo. 1910. Diccionario etimolójico de las voces chilenas derivadas de lenguas indijenas americanas. Santiago de Chile: Cervantes.

LIENHARD, MARTín. 1994. Oralidad. Revista de crítica literaria latinoamericana 20, 20: 371 374 [en línea]. Disponible en http://www.jstor.org/stable/pdf/4530780.pdf.

Luco Cruchaga, Germán. 1958. La viuda de Apablaza. Santiago de Chile: Del Nuevo Extremo.

Mancera Rueda, Ana. 2008. La reformulación en el discurso periodístico: una muestra de oralidad fingida. Oralia 11: 353-374.

Martínez Albarracín, Carmen. 1993. La lengua coloquial en el teatro en la guerra. En Miguel Hernández cincuenta años después: actas del I Congreso Internacional (pp. 759-766). Alicante, Elche, Orihuela, marzo de 1992.

MEyer RusCa, WaLterio. 1952. Voces indígenas del lenguaje popular sureño. 550 chilenismos. Padre Las Casas: Imp. San Francisco.

Morales Pettorino, Félix; Óscar Quiroz Mejías y Juan José Peña Álvarez. 1984. Diccionario ejemplificado de chilenismos y de otros usos diferenciales del español de Chile (Vol. I A-Caz). Valparaíso: Academia Superior de Ciencias Pedagógicas de Valparaíso.

1985. Diccionario ejemplificado de chilenismos y de otros usos diferenciales del español de Chile (Vol. II CC-Grup). Valparaíso: Academia Superior de Ciencias Pedagógicas de Valparaíso.

1986. Diccionario ejemplificado de chilenismos y de otros usos diferenciales del español de Chile (Vol. III Gua-Peq). Valparaíso: Universidad de Playa Ancha de Ciencias de la Educación.

Morales Pettorino, Félix; Óscar Quiroz Mejías; Antonio Riffo Farías y Cecilia Copello CRUZ. 1987. Diccionario ejemplificado de chilenismos y de otros usos diferenciales del español de Chile (Vol. IV Per-Z, Suplemento). Valparaíso: Universidad de Playa Ancha de Ciencias de la Educación.

"Murió Actor Chileno Roberto Navarrete". 2 septiembre 1999. El Mercurio [en línea]. Recuperado de http://diario.elmercurio.com/detalle/index.asp?id=\{72babf2e-2678-4c5ea60e-dcba3744fec1\}. 
NARBona, ANTONIO. 2012. Los estudios sobre el español coloquial y la lingüística. Revista de la Sociedad Española de Lingüística 42, 2: 5-31. [en línea]. Disponible en https://idus. us.es/xmlui/handle/11441/29165.

Navarrete, Roberto. 1987. Los herederos de las moscas. Santiago de Chile: Génesis.

NúÑEz, JosÉ María. 27 de mayo de 1842. Al señor redactor de El Mercurio. El Mercurio de Valparaiso. En Norberto Pinilla. 1945. La controversia filológica de 1842 (pp. 49-53). Santiago de Chile: Prensas de la Universidad de Chile.

Oesterreicher, Wulf. 1996. Lo hablado en lo escrito. Reflexiones metodológicas y aproximación a una tipología. En Thomas Kotschi, Wulf Oesterreicher y Klaus Zimmermann (eds.). El español hablado y la cultura oral en España e Hispanoamérica (pp. 317-340). Madrid: Iberoamericana.

Oroz, Rodolfo. 1966. La lengua castellana en Chile. Santiago de Chile: Editorial Universitaria.

PARRA, RoBerto. 2009. La Negra Ester: décimas ilustradas. Valparaíso: Quilombo Ediciones.

Pérez, Hernán Emilio. 2007. Estudio de la variación estilística de la serie /b-d-g/ en posición intervocálica en el habla de los noticieros de la televisión chilena. Estudios de Fonética Experimental XVI: 227-259 [en línea]. Disponible en http://www.raco.cat/index.php/ EFE/article/view/140053.

Pescador, María José. Junio 2011. Territorio mágico. El Valle del Cachapoal. Tell Magazine [en línea]. Recuperado de http://www.tell.cl/magazine/1344/rancagua/junio/2011/reportajes/ territorio-magico.html.

Piña, Juan ANDRÉs. 1990. Antonio Acevedo Hernández, fundador del Teatro Social. En Antonio Acevedo Hernández, Chañarcillo. Santiago de Chile: Pehuén.

Poblete Vallejos, Mario; Hernán Pons Galea y José Luis Samaniego Aldazábal. 2000. Fenómenos gramaticales y recursos modalizadores del enunciado en el español culto de Santiago de Chile. Onomázein 5: 143-151 [en línea]. Disponible en https://repositorio. uc.cl/bitstream/handle/11534/7848/000326162.pdf?sequence $=1$.

Pons, Hernán y José Luis SAmaniego. 1998. Marcadores pragmáticos de apoyo discursivo en el habla culta de Santiago de Chile. Onomázein 3: 11-25 [en línea]. Disponible en https:// repositorio.uc.cl/bitstream/handle/11534/7794/000275775.pdf?sequence=1.

Rabanales, Ambrosio. 2000. El español de Chile: presente y futuro. Onomázein 5: 135-141 [en línea]. Disponible en http://www.redalyc.org/html/1345/134518327009/.

Real Academia Española (RAE) y Asociación de Academias de la Lengua Española (ASALE). 2009. Nueva gramática de la lengua española. Morfología y sintaxis I. Madrid: Espasa Libros.

2014. Diccionario de la lengua española (23 a ed.). Versión en línea disponible en http://www.rae.es.

Rodríguez Fernández, Mario. 1999. Parra, un poeta menor. Universum 14: 287-290 [en línea]. Disponible en http://universum.utalca.cl/contenido/index-99/rodriguez.pdf.

Ruiz Velasco, Liliana. 2016. La oralidad en la telenovela: del medio a la construcción lingüístico-discursiva. Círculo de Lingüística Aplicada a la Comunicación 67: 297-317 [en línea]. Disponible en http://revistas.ucm.es/index.php/CLAC/article/ viewFile/53486/49043.

SÁez Godoy, Leopoldo. 1999. El español de Chile en las postrimerías del siglo XX. Santiago de Chile: Bachillerato en Ciencias y Humanidades, Universidad de Santiago de Chile.

San Martín NúÑEz, Abelardo. 2011. Los marcadores interrogativos de control de contacto en el corpus PRESEEA de Santiago de Chile. Boletín de Filología XLVI, 2: 135-166 [en línea]. Disponible en http://www.scielo.cl/scielo.php?pid=S071893032011000200006\&script $=$ sci_arttext\&tlng=pt.

Sievering, Alejandro. 2003. Ánimas de día claro. Santiago de Chile: Editorial Universitaria. 
Soto-BARBA, JAIME. 2011. Variación consonántica en el habla urbana y rural de la provincia de Ñuble. Revista de Lingüistica Teórica y Aplicada 49, 2: 111-127 [en línea]. Disponible en http://www.scielo.cl/scielo.php?pid=S0718-48832011000200006\&script=sci arttext\&tlng=en.

Soto-Barba, Jaime; Erika Díaz y Daniel Ignacio Pereira. 2015. Variación alofónica y diatópica del fonema/b/en el español de profesionales chilenos en situación de lectura en voz alta. Literatura y Lingüistica 32: 201-216 [en línea]. Disponible en http://www.scielo.cl/scielo. php?pid=S0716-58112015000200011\&script=sci_arttext.

Valencia Espinoza, Alba. 2010. Expresiones zoomórficas en el habla chilena coloquial. En Rosa Castañer Martín y Vicente Lagüéns Gracia (eds.). De moneda nunca usada. Estudios dedicados a José M. ${ }^{a}$ Enguita Utrilla (pp. 593-604). Zaragoza: Institución "Fernando el Católico" (C.S.I.C.) [en línea]. Disponible en https://ifc.dpz.es/recursos/ publicaciones $/ 29 / 95 /$ ebook.pdf\#page=595. editorial. 